\title{
Designing rigorous and relevant learning experiences for future teachers
}

\author{
Daniela-Maria Creţu $^{1 *}$ \\ 1“"Lucian Blaga” University, Teacher Training Department, 34 Calea Dumbrăvii 550324 Sibiu, \\ Romania
}

\begin{abstract}
Teaching and learning at the university should help students develop complex thinking about the issues they are dealing with and practice skills needed to solve real-world problems. The Rigor/Relevance Framework, developed by the staff of the International Center for Leadership in Education (ICLE), is a useful tool for designing learning experiences that increase the rigor and the relevance of the curriculum. This model integrates Bloom's taxonomy with its six levels (remembering, comprehension, application, analysis, synthesis, and evaluation) with the Application Model, which has five levels (knowledge in one discipline, apply in discipline, apply across disciplines, apply to real-world predictable situations and apply to real-world unpredictable situations). The combination of these two dimensions results in four quadrants: Acquisition, Application, Assimilation, Adaptation, in which learning experiences can be designed to raise the rigor and relevance of instruction. The aim of this study is to exemplify the use of the Rigor/Relevance Framework in designing the learning experiences offered during two courses for future teachers for primary and preschool education. The implications of selecting appropriate instructional strategies and student assessment methods are discussed.
\end{abstract}

\section{Introduction}

When the students graduate higher education, they should be career ready for the complex and dynamic 21 st-century and prepared to succeed in the world they will face. Higher education must to develop the knowledge, the skills and the attitudes the students need to succeed in life and in career. Students approach a wide range of disciplines during their university study. Sometimes, however, students do not understand the necessity and relevance of these disciplines for their future profession. The traditional teaching methods practiced by some teachers, overly theoretical content, the emphasis on information reproduction, non-challenging learning tasks can feed such a perception. If we want young university graduates to integrate into the labor market and build successful careers in such a dynamic world, then they need more than memorize, they need to learn how to think and how to use what they have learned in the world in which they will live and work. A way to do this is to reshape the practice of teaching and learning in higher education. Teaching and

${ }^{*}$ Corresponding author: daniela.cretu@ulbsibiu.ro 
learning at the university should help students develop complex thinking about the issues they are dealing with and practice skills needed to solve real-world problems. Moving the focus from knowledge acquisition and memorization to knowledge application and skills such as: problem solving, critical thinking and creativity is a real need, but also a challenge for academics and students, too.

For this reason, adding rigor and relevance to instruction to meeting learner needs and higher achievement goals are extremely useful. But how can this be done? An extremely useful tool for this purpose is The Rigor / Relevance Framework, developed by the staff of the International Center for Leadership in Education [1]. Designing more rigorous and relevant curriculum-based learning experiences, the selection of appropriate instructional and assessment strategies can be addressed with this framework. The aim of this study is to exemplify the use of the Rigor / Relevance Framework in designing the learning experiences offered during two courses for future teachers for primary and preschool education.

\section{The Rigor and Relevance Framework}

The Rigor and Relevance Framework is based on two dimensions: a vertical one, which is the revised Bloom's taxonomy, describing increasingly complex levels of thinking and a horizontal one, represented by the Application Model, which describes five increasingly complex levels of putting information into action [1].

The six levels of the revised Bloom's Taxonomy are: remembering, understanding, applying, analyzing, evaluating, and creating [2].

- Remembering refers to acquiring knowledge, recognizing or recalling knowledge from memory.

- Understanding means constructing meaning from material, by interpreting, exemplifying, classifying, summarizing, or explaining.

- Applying involves the ability to carry out or to use a procedure through executing or implementing.

- Analyzing means breaking materials or concepts into parts, determining how the parts relate to one another or how they interrelate.

- Evaluating involves making judgments based on criteria and standards through checking and critiquing.

- Creating requires putting elements together to form a coherent or functional whole, reorganizing elements into a new pattern or structure.

When students move from lower (first three) to higher levels (the last three) in approaching curriculum themes, they move from acquiring knowledge to assimilation of knowledge. Rigor is fostered in academic environments or settings in which students are expected and supported to learn at high levels of knowledge taxonomy. Rigor is scaffolding and planning for thinking, recognizing the level of thinking students demonstrate, managing the teaching / learning level for the desired thinking level and it doesn't imply solving more or harder worksheets, more homework, higher level reading or math problems [3]. Sztabnik considers that rigor is the result of work that challenges students' thinking in new and interesting ways and is happening when they are encouraged towards a sophisticated understanding of fundamental ideas and are driven by curiosity to discover what they do not know [4]. Daggett and Gendron see rigorous learning as a bridge from the classroom to the students' future, long-term success [5]. Rigor means framing courses, seminars, practical activities with students at the high end of the knowledge taxonomy. In rigorous instructional activities, students are encouraged to: examine, generate, produce, evaluate, create, decide, etc. 
The second dimension (the horizontal axis) is the Application Model, which describes the degree to which a student applies the knowledge in solving different problems. It has five levels: knowledge in one discipline; apply in discipline; apply across disciplines; apply to real-world predictable situations and apply to real-world unpredictable situations [1]. This model involves the transition from acquisition of knowledge to application of knowledge, where the knowledge is used for solving complex real-world problems or situations. A relevant course or seminar ask students to use their knowledge to approach real-word problems that have multiple solutions.

The combination of these two dimensions results in four quadrants: A) Acquisition; B) Application; C) Assimilation; D) Adaptation (Figure 1).

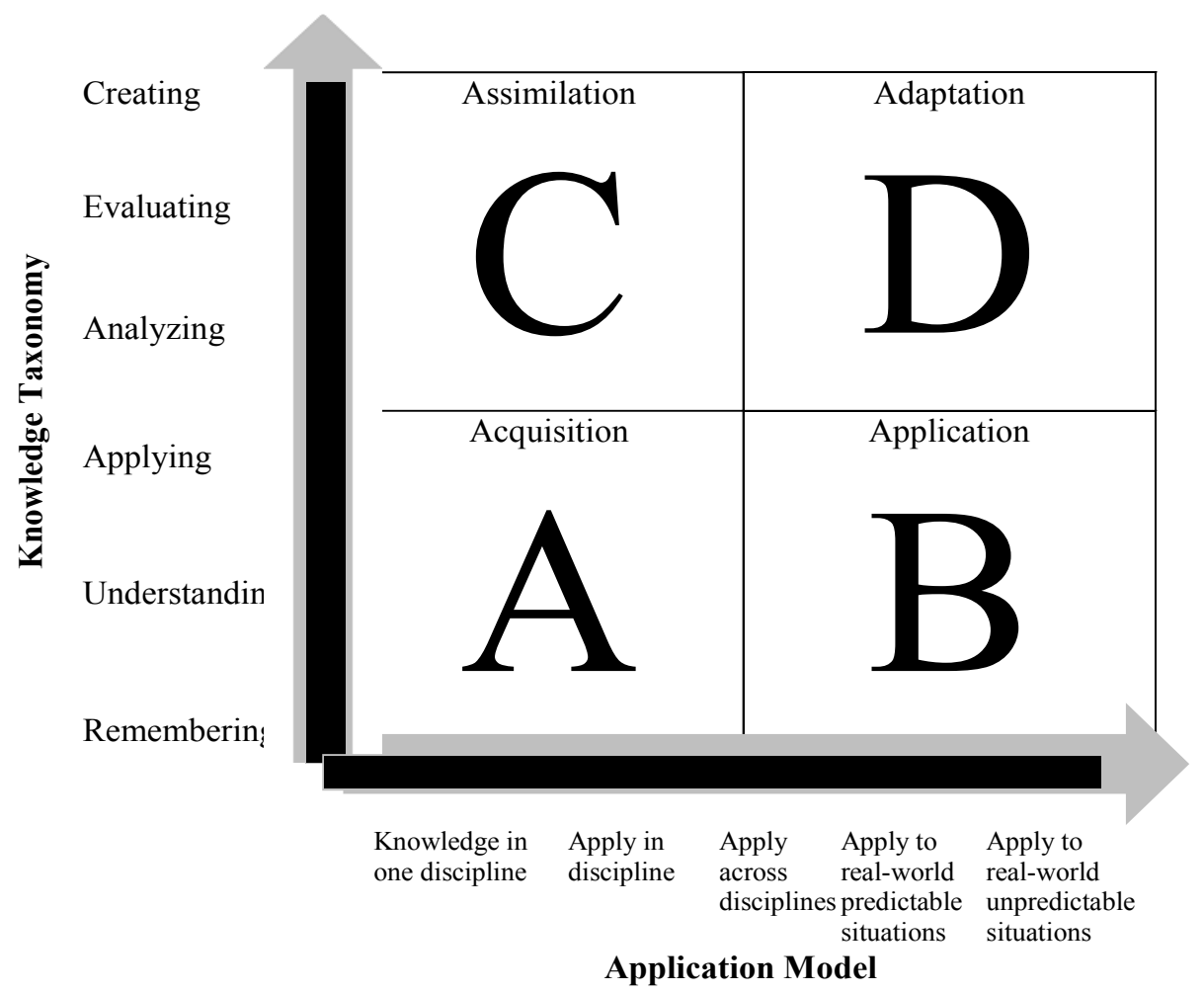

Fig. 1 The Rigor and Relevance Framework [1]

In the following, we present these quadrants, as well as the actions and products that can be achieved by students within each quadrant [1]:

- Quadrant A represents simple recall and basic understanding of knowledge for its own sake. Students are expected to remember or understand the acquired knowledge. The teaching-learning activities that enroll in this quadrant require students to: recite, recall, name, memorize, match, list, label, identify, describe, define, count, etc. As student work products, we mention: definitions, explanations, lists, recitations, true-false answers etc.

- Quadrant B involves the use of acquired knowledge to solve problems, design solutions and complete work. In this quadrant, students are required to: solve, relate, produce, make, interview, follow, draw, demonstrate, construct, build, apply, etc. The 
products can take the form of: collages, data, demonstrations, paintings, solutions, surveys, interpretations etc.

- Quadrant C implies higher levels of knowledge, such as analyzing, solving problems and creating unique solutions. The students are challenged to: analyze, research, compare, debate, evaluate, judge, justify etc. and can produce: charts, debates, essays, exhibits, inventories, journals, investigations, plans, reports, etc.

- Quadrant D represents thinking in a complex way and applying knowledge and skills acquired. The students' work and learning within this quadrant requires to: adapt, argue, compose, create, design, invent, modify, prioritize, revise, teach. They can produce: brochures, games, lessons, newspapers, poems, songs, videos, websites, etc.

The teachers can use framework to add rigor and relevance in instruction, by designing, teaching and learning experiences for their students, aligned with the instructional learning goals and by choosing assessment tasks accordingly. An authentic assessment is focused on upper-level of the knowledge taxonomy (high rigor) and challenges students to apply the knowledge to real-world problems (high relevance). The Rigor and Relevance Framework is compatible with Biggs' constructive alignment theory, which is an approach to curriculum design that optimizes the conditions for quality learning, based on: defining the intended outcomes (the objectives); choosing teaching/learning activities likely to lead to attaining the objectives; assessing students' learning outcomes to see how well they match what was intended $[6,8]$.

There is a need to help teachers shift their instruction and expectations from Quadrant A (with low rigor and low relevance) to Quadrant D (with high rigor and high relevance) [7]. In Quadrant D the students think analytically and creatively and they are gaining the skills to apply information to a range of real-world situation [5].

\section{Designing rigorous and relevant learning experiences for students - results and discussion}

Rigor and Relevance learning begins with the design of instruction by teacher, which implies decisions on setting goals, choosing teaching and learning activities and student assessment. In the following we will illustrate how we used the Rigor and Relevance framework to design learning activities within two academic disciplines, for students enrolled in a study program for the teaching profession at a Romanian university. The two disciplines are: Theory and Methodology of Instruction and Methodology of Educational Research. Based on the content analysis of the syllabus of each discipline, we designed student learning tasks according to the four quadrants within the Rigor and Relevance framework. In the following, we will present the objectives of each discipline, followed by planned learning activities.

The first selected course is called Theory and Methodology of Instruction and is designed for 2 nd year students. The course requires 2 hours of lecture and one hour of seminar per week, for one semester. At the end of this course, the students are expected: to explain the concepts specific to the theory and methodology of instruction; to analyze the principles and teaching methods specific to primary and pre-primary education; to apply principles and methods of training on various instructional sequences; to exercise didactic design in accordance with the curriculum for primary and preschool education; to explore trends in the evolution of instructional practice in primary and pre-primary education; to show openness to the innovation trends of the instructional process. In Table 1 we present specific learning activities for each of the 4 quadrants, within the Theory and Methodology of Instruction course. Most of these learning activities were implemented in courses and seminars. Some of these have been identified during the elaboration of the present paper and are a good source of inspiration for the work with the future students. 
Table 1. Designed learning activities for students in the course - Theory and methodology of instruction

\section{D}

- Take a stance based on arguments on the topic of homework: "It would be a good idea to drop homework in primary school classes".

- How will schools / kindergartens look over 20 years? In what ways will the teacher's activity change? Make an inventory of ideas or a poster about it.

- Write an essay on the theme: Fostering children creativity in kindergarten/ school. Give and seek feed-back in pairs in order to improve the writing.

- Compare the school where you studied with the school where you are doing practicum, using at least 5 criteria.

- Compare teacher-centered instruction with student-centered instruction.

- Compose a quintet about one instructional methods (of your choice).

- After watching an educational film, analyze at least five ideas that you could use in teaching children. Argument your options.

- Keep a learning journal on the course. A

- Identify the different categories and subcategories in which the methods are classified. Make a list of them.

- Describe instructional methods (brainstorming, debate, observation, study case, demonstration, game, lecture, jigsaw, reciprocal teaching, thinking hats, role play, projects etc.).

- Match between the method's name and its description.

- Make a list of at least 10 instructional methods appropriate in kindergarten and primary school.

- Present the levels and requirements of the instructional design.

- Define common terms used in the course.
- What possible solutions can be found for preventing and reducing the violence in schools? Make a plan of measures for a primary school in the urban area.

- Plan a summer camp or an after-school program for primary school children. Make a poster or an ad about this.

- Make a brochure with games for preschoolers/primary school students.

- How would you designe a curriculum for a private/public kindergarten/ school.

- Design and teach a learning activity for preschool / primary school pupils.

- Design activities for children, covering the "Different School" one week program (choose the class level).

- Design an inclusive school which is ready to receive pupils with different educational needs too.
- Observe in pedagogical practice the implementation of at least five teachinglearning methods. Identify the strengths and limitations of the methods.

- On a subject from the preschool / primary curriculum, develop learning activities from the perspective of multiple intelligence theory.

- Write a report on how the program "Different School" was organized in the institution where you do practicum.

- Make an interview with a teacher on one educational theme (Teaching methods; Successful and unsuccessful experiences in student instruction; Active learning, etc.).

- Formulate an "I" message for a situation related to school (for instance, a student interrupts while you teach).

- Make a role-play to illustrate active listening in teacher-student communication. 
In the following, we provide an example of an activity in each quadrant.

- Quadrant A: Make a list of at least 10 appropriate methods of instructional methods appropriate in kindergarten and primary school. This was an individual activity. We present a student's list: play-based instruction, story-telling, and discussions, hands-on learning, classroom experiments, observation, graphic organizers, questioning, cooperative learning, direct-instruction, brainstorming.

- Quadrant B: Formulate an "I" message for a situation related to school (for example, a student interrupts while you teach). This was an individual activity. Here is the message which was written by a student: "When you talk while I teach, I feel disturbed, because I lose my set of ideas. I want you to wait for me to finish my idea, and then talk".

- Quadrant C: Compose a quintet about one instructional method (of your choice). This was an individual activity. We present an example of a quintet created by a student, about brainstorming methods: "Brainstorming/ Creative, Dynamic/ Challenges, searches, produces/ Innovative ideas, without criticism/ Development."

- Quadrant D: Design and teach a learning activity for preschool / primary school pupils. The students have the freedom to choose how to approach the task: individually or in groups (up to three members). Future teachers selected from the curriculum the knowledge and skills and used different methods to teach them for their colleagues, during the assigned time (20-30 minutes). In the end, they received feedback from colleagues, teachers, and conducted a self-analysis of micro-teaching. The way in which this experience was prepared and realized for students was widely reported in another paper [8].

The second course that we want to exemplify for the application of the Rigor and Relevance Framework is the Methodology of Educational Research. This course is also followed by students enrolled in the program for the teaching profession (pre-school and primary education) in the second year, for one semester, with two hours of lectures and one hour of seminar. It is the only course of initiation for students in the field of research in education within the study program and it is extremely useful for the students considering that they have to prepare and present a bachelor's degree (which involves to carry out an investigation in the educational environment).

At the end of this course, the students are expected: to acquire concepts and scientific investigation procedures in the field of education; to describe the stages of pedagogical research; to characterize methods of investigation specific to the educational field; to apply the research methods specific to the educational field; to practice the ways of ordering, processing and interpreting data; to analyze the various types of research in education; to design a research on a chosen subject; to get involved in research in education in order to find optimal solutions to the problems inherent in the educational act; to explore the opportunities that research in education offers to future teachers.

As with the previous course, we present activities designed for this discipline in line with The Rigor and Relevance Framework (Table 2). We provide a Quadrant B activity as an example: Develop an interview guide on a theme (at your choice). A student teacher chose to develop an interview guide for fourth-class students about homework issues. Here's what the interview guide looks like: 1. How often do you get homework from teachers?; 2. How often do you do your homework?; 3. How much do you spend daily/ weekly, solving homework?; 4. Are there people who help you to do the homework? How do these people engage in performing homework?; 5. Do teachers check your homework? Does it help you to correct the homework?; 6. Do you like doing homework? Why or why not?; 7. What is your opinion about the role of homework? Is it useful or not for learning? Argument your position.; 8. If you could say a message to your teacher about homework, what would that be? 
Table 2. Designed learning activities for students in the course - Methodology of research in education

\section{C $\quad$ D}

- Evaluate an educational research based on given criteria.

- Argument the importance of research for educational theory and practice.

- Analyze an educational research in the scientific literature (journal articles, conference papers).

- Create a list of possible research topics in education, taking into account the trends in education in the 21 st century.

- Analyze a school problem, suggest a solution, and prepare a plan to solve it.

- Plan ,the day of the research teacher” within a school.

- Write a scientific article for the annual scientific student conference.

- How would you devise your own way to deal with your educational research project?

A

- List research methods used in education.

- Describe the stages of an educational research project.

- Give examples of research questions for a research project.

- Present the features of an action research.

- Explain the ethical issues to be pursued in a research.

- Make a graphic organizer about a research method in education.

\section{B}

- Organize the data of a survey.

Represent the data through the statistical graph.

- Write a research letter to the school board in which you ask for permission to do your research.

- Develop an interview guide on a theme (at your choice) and interview with students, teachers, or headmasters.

- Complete an observation grid of teacher or student activity in the classroom (in various disciplines).

- Make a bibliographic list on a research topic of your choice.

As it can be seen from Tables 1 and 2, the students receive learning experience coming from all four quadrants. The activities in quadrant A constitute the foundation, support for the more sophisticated activities in quadrants B, C, and especially in D, where thinking is complex and application to real-world situations is obvious. The course and seminars contexts offer many opportunities for students to respond to knowledge-based tasks that emphasize high-level thinking skills, creativity and the ability to connect what they are learning with real-world applications. The students use different sources of information (books, articles, lecture content, video, film, internet resources) to complete the rigor and relevance learning task. Courses take place in the spirit of active and interactive learning, and whole class activities alternate with group and individual activities. The learning environment is based on mutual respect between teacher and students and positive relationships.

We promote instructional strategies in courses and seminars which reflect rigor and relevance and which are appropriate to each quadrant. For instance, we use interactive lecture, memorization, guided reading, teacher questions, note-taking, graphic organizers, exercise (for Quadrant A); observation, demonstration, role-playing, interview, (for Quadrant B); essays, contrast and compare, brainstorming, quintet, think-pair-share, value line, study-case, video, reflection, debates, teacher questions (for Quadrant C); presentations, exhibitions, teaching others, tour gallery, project design, research, independent learning (for Quadrant D). As assessment methods, we use the combination of the written test (with questions corresponding to all levels in the Bloom taxonomy), portfolio (where students integrate products made during the semester: lesson projects, 
projects for learning situations, research projects, essays, posters, letters, analysis of case studies, questionnaires, interview guides, etc.) and student activity seminars: demonstrations, cooperative learning, presentations and exhibitions.

\section{Conclusions}

This study illustrates the use of the Rigor / Relevance Framework in the design of the learning experiences offered during two courses for future teachers for primary and preschool education. We have provided examples of learning activities for students who covered all 4 quadrants of the framework approached. Designing learning activities from the perspective of the Rigor and Relevance Framework forces the teacher to think less about how he teaches or what he does, but more about how students learn and what they do. This approach is less about teachers and more about students. It offers the opportunity for teachers to experience that teaching is about organizing and supporting learning experiences for students, by coordinating and facilitating the learning. The students are active, engage, and develop skills needed in the future work environment.

We believe that the learning experiences experienced by students in these two disciplines are valuable because the students we worked with will be tomorrow's teachers for preschool and primary school students. The diversity of instructional methods, the focus on active and interactive learning, reflection, feed-back, creativity, investigation, rigor and relevance can inspire the type of educational approach that these future teachers can have in their work. We express our hope that today's students will continue this methodological direction by integrating and developing new pedagogical approaches according to the specifics of the children they will work with and to what they need to know and do, to succeed in school and later in their career. Every teacher has the power to increase rigor in his or her classes and to have a positive impact on the students' ways of thinking. Providing rigorous and relevant learning experiences to all students in higher education is a possibility and a necessity in order to support their development and prepare them for life and career.

\section{References}

1. W.R. Daggett, Rigor \& Relevance Framework.. Retrieved from http://www.leadered.com/pdf/Rigor\%20Relevance\%20Framework\%20White\%20Paper\%20201 6.pdf (2016)

2. L. W. Anderson, D. R. Krathwohl (Eds.), A Taxonomy for Learning, Teaching, and Assessing: A Revision of Bloom's Taxonomy of Educational Objectives (Pearson Education Group, 2001)

3. A. Deatrick, S. Slater, C. Stansifer, Integrating Tech While Building Rigor and Relevance into Instruction and Assessment (2018). Retrieved from https://fp37.a2zinc.net/clients/GHEvents/MACUL18/Public/SessionDetails.aspx?FromPage=Ses sions.aspx\&SessionID $=38 \&$ SessionDateID $=1$

4. B. Sztabnik, A New Definition of Rigor, Edutopia. (2015). Retrieved from https://www.edutopia.org/blog/a-new-definition-of-rigor-brian-sztabnik

5. W.R. Daggett, S.A. Gendron, Rigorous learning: Bridging students from our classrooms to successful lives, ICLE Retrieved from

http://www.leadered.com/pdf/2015MSC_BridgingStudentsFromOurClassroomstoSuccessfulLive s.pd (2015)

6. J.B. Biggs, Teaching for quality learning at university (Buckingham, The Open University Press, 2003)

7. B. Daggett, Addressing Current and Future Challenges in Education, ICLE (2014). Retrived from http://www.leadered.com/pdf/2014MSC_AddressingCurrentandFutureChallenges.pdf

8. D. Crețu, Fostering $21^{\text {st }}$ century skills for future teacher, The European Proceedings of Social and Behavioural Sciences, 23, 672-681, doi: 10.15405/epsbs.2017.05.02.82 (2017) 